\title{
บUsisersily
}

\section{Understanding the lived experiences of healthcare professionals during the COVID-19 pandemic: an interpretative phenomenological analysis}

McGlinchey, E., Hitch, C., Butter, S., McCaughey, L., Berry, E., \& Armour, C. (2021). Understanding the lived experiences of healthcare professionals during the COVID-19 pandemic: an interpretative phenomenological analysis. European Journal of Psychotraumatology, 12(1), [1904700].

https://doi.org/10.1080/20008198.2021.1904700

Link to publication record in Ulster University Research Portal

Published in:

European Journal of Psychotraumatology

Publication Status:

Published online: 30/04/2021

DOI:

10.1080/20008198.2021.1904700

\section{Document Version}

Publisher's PDF, also known as Version of record

\section{General rights}

Copyright for the publications made accessible via Ulster University's Research Portal is retained by the author(s) and / or other copyright owners and it is a condition of accessing these publications that users recognise and abide by the legal requirements associated with these rights.

\section{Take down policy}

The Research Portal is Ulster University's institutional repository that provides access to Ulster's research outputs. Every effort has been made to ensure that content in the Research Portal does not infringe any person's rights, or applicable UK laws. If you discover content in the Research Portal that you believe breaches copyright or violates any law, please contact pure-support@ulster.ac.uk. 


\section{Understanding the lived experiences of healthcare professionals during the COVID-19 pandemic: an interpretative phenomenological analysis}

\section{Emily McGlinchey, Catherine Hitch, Sarah Butter, Laura McCaughey, Emma Berry \& Cherie Armour}

To cite this article: Emily McGlinchey, Catherine Hitch, Sarah Butter, Laura McCaughey, Emma Berry \& Cherie Armour (2021) Understanding the lived experiences of healthcare professionals during the COVID-19 pandemic: an interpretative phenomenological analysis, European Journal of Psychotraumatology, 12:1, 1904700, DOI: 10.1080/20008198.2021.1904700

To link to this article: https://doi.org/10.1080/20008198.2021.1904700
(c) 2021 The Author(s). Published by Informa UK Limited, trading as Taylor \& Francis Group.
Submit your article to this journal ๔

\section{Q View related articles ¿}

Published online: 30 Apr 2021.

山ll Article views: 5415

View Crossmark data $₫$ 


\title{
Understanding the lived experiences of healthcare professionals during the COVID-19 pandemic: an interpretative phenomenological analysis
}

\author{
Emily McGlinchey (D) $^{a}$, Catherine Hitch ${ }^{a}$, Sarah Butter ${ }^{a}$, Laura McCaughey ${ }^{a}$, Emma Berry ${ }^{b}$ \\ and Cherie Armour (iD ${ }^{a, b}$
}

aStress Trauma and Related Conditions (STARC) Research Lab, School of Psychology, Queen's University Belfast, Belfast, Northern Ireland, UK; 'bentre for Improving Health Related Quality of Life (CIHRQoL), School of Psychology, Queen's University Belfast, Belfast, Northern Ireland, UK

\begin{abstract}
Background: Little research has examined the impact of working within the context of COVID-19 on UK healthcare professionals (HCPs) mental health and well-being, despite previous pandemic findings indicating that HCPs are particularly vulnerable to suffering PTSD and other mental health difficulties due to the nature of healthcare work. Specifically, it appears that no research has employed qualitative methodologies to explore the effects of working amidst COVID-19 on mental health for HCPs in the UK.

Objective: To qualitatively examining the lived experiences of HCPs in Northern Ireland, working during the early stages of the pandemic and lockdown period (14.04.20 and 29.04.20).

Method: Interpretative phenomenological analysis (IPA) was used to explore the experiences of healthcare professionals, who were working during the COVID-19 outbreak. Ten HCPs were recruited via a social media campaign and snowball sampling. All interviews were conducted via telephone and transcribed verbatim.

Results: Three superordinate themes with subordinate themes were elicited through the analysis. Theme one centred on specific challenges of HCPs working during the pandemic, such as redeployment, isolation from loved ones, infection concerns, lack of PPE and impact on patient interpersonal care. Theme two offered insights into the mental health and wellbeing of HCPs, while many experienced feelings of fear, sadness and hypervigilance, all also demonstrated a marked resilience. Finally, many felt undervalued and misunderstood, and wished to press upon the general public seriousness of the disease.

Conclusion: To the authors' knowledge this is the first study to explore in depth, the unique experiences of frontline HCPs in Northern Ireland, offering a detailed account of the challenges confronted in these unprecedented circumstances and highlighting support needs within this cohort.
\end{abstract}

\section{Comprendiendo las experiencias vividas de los profesionales de la salud durante la pandemia de COVID-19: un análisis fenomenológico interpretativo}

Antecedentes: Pocas investigaciones han examinado el impacto de trabajar en el contexto COVID-19 en la salud mental y bienestar de los profesionales de salud del Reino Unido (HCPs por sus siglas en inglés), a pesar que los hallazgos de pandemias previas señalan que los HCPs son particularmente vulnerables a sufrir TEPT y otras dificultades de salud mental debido a la naturaleza del trabajo sanitario. Específicamente, pareciera que ninguna investigación ha utilizado metodologías cualitativas para explorar los efectos de trabajar en medio de COVID-19 en la salud mental de los HCPs en el Reino Unido.

Objetivo: Examinar cualitativamente las experiencias vividas de los HCPs en Irlanda del Norte, trabajando durante las primeras etapas de la pandemia y el periodo de confinamiento (14.04.20 y 29.04.20).

Método: Se utilizó un Análisis fenomenológico interpretativo (IPA por sus siglas en inglés) para explorar las experiencias de los profesionales de la salud, que estuvieron trabajando durante el brote de COVID-19. Fueron reclutados diez HCPs a través de una campaña por medios sociales y un muestreo de bola de nieve. Todas las entrevistas se realizaron por teléfono y se transcribieron literalmente.

Resultados: A través del análisis se obtuvieron tres temas superiores con temas subordinados. El tema uno se centró en los desafíos específicos de los HCPs que trabajaban durante la pandemia, como el redespliegue, estar aislados de los seres queridos, preocupaciones de infectarse, falta de EPP y el impacto en la atención interpersonal del paciente. El tema dos ofreció concientización sobre la salud mental y bienestar de los HCPs, aunque muchos experimentaron sentimientos de miedo, tristeza e hipervigilancia, todos también demostraron una marcada resiliencia. Finalmente, muchos se sintieron subvalorados y poco comprendidos y desearon presionar al público en general sobre la gravedad de la enfermedad.
ARTICLE HISTORY

Received 27 November 2020

Revised 26 February 2021

Accepted 6 March 2021

\section{KEYWORDS}

COVID-19; healthcare professionals; psychological wellbeing; qualitative research; mental health

\section{PALABRAS CLAVE}

COVID-19; profesionales de la salud; bienestar psicológico; investigación cualitativa; salud mental

\section{关键词}

COVID-19; 医护人员; 精神 健康; 定性研究; 心理健康

\section{HIGHLIGHTS}

- The current study qualitatively examines the experiences of frontline healthcare professionals working during the early stages of the COVID-19 pandemic in the UK.

- Three superordinate themes with subordinate themes emerged from the analysis, broadly covering key areas such as navigating new occupational challenges, maintaining mental health and wellbeing under precedented circumstances, and managing feelings being misunderstood and undervalued.

- Specific challenges included sudden redeployment, resulting often in a change in job role (and/or location) as well as a loss of important work related social networks because of this, isolation from loved ones, infection concerns, lack of (or limited supply of) personal protection equipment and impact on patient interpersonal care.

- The findings suggest that being a healthcare professional during this time

CONTACT Emily McGlinchey e.mcglinchey@qub.ac.uk School of Psychology, Queen's University Belfast, Belfast, Northern Ireland, UK

*Present address: Department of Psychology, The University of Sheffield, Sheffield, UK.

(c) 2021 The Author(s). Published by Informa UK Limited, trading as Taylor \& Francis Group.

This is an Open Access article distributed under the terms of the Creative Commons Attribution-NonCommercial License (http://creativecommons.org/licenses/by-nc/4.0/) which permits unrestricted non-commercial use, distribution, and reproduction in any medium, provided the original work is properly cited. 
Conclusión: Según el conocimiento de los autores, este es el primer estudio que explora en profundidad, las experiencias únicas de los HCPS de primera línea en Irlanda del Norte, ofreciendo un recuento detallado de los desafíos enfrentados en estas circunstancias sin precedentes y destaca las necesidades de apoyo dentro de esta cohorte.

\section{了解COVID-19疫情期间医护人员的亲身经历：一项解释性现象学分析}

背景: 尽管先前疫情研究表明, 英国医护专业人员 (HCP) 因医护工作性质格外易感PTSD和其他 精神疾病困扰，很少有研究考查在COVID-19背景下工作对HCP心理健康的影响。具体而言，似 乎没有研究采用定性方法来探究英国HCP在COPID-19中工作对其心理健康的影响。

目的: 定性考查在疫情和封锁期间 (14.04.20和29.04.20) 早期工作的北爱尔兰HCP的亲身经历。 方法: 使用解释性现象学分析 (IPA) 来探讨COVID-19爆发期间工作的医护人员的经历。通 过社交媒体活动和滚雪球采样招募了十组 HCP。所有访谈均通过电话进行，并逐字记录。 结果: 通过分析得出了三个有子主题的上级主题。主题一集中在疫情期间HCP工作的特定挑 战，例如人员调动，与亲人隔离，感染问题，缺乏PPE以及对患者人际关怀的影响。主题二提供 了对HCP心理健康和幸福的见解, 尽管经历了许多恐惧, 悲伤和高警觉的感觉, 大家都表现出明 显的心理韧性。最后, 许多人感到被低估和被误解了，并希望向公众强调这种疾病的严重性。 结论: 据作者所知，这是首篇深入探究北爱尔兰前线HCP独特经历的研究，详细介绍了此群 体在这些前所未有情况下面临的挑战, 并强调了支持他们的需求。 does not come without personal cost and has the potential to put pressure on one's psychological state, with many participants experienced feelings of fear, sadness and hypervigilance, as well as physical exhaustion.

- All participants

demonstrated a marked resilience in their ability to continue to do navigate their work environment and were able to employ adaptive coping strategies however, some expressed concern that this is waning. It is essential that we do not neglect a workforce which is working tirelessly at great personal cost to keep each one of us safe and support the continued wellbeing and resilience of healthcare professionals.

- It is argued that in order to adequately support healthcare professionals physical and mental health we must tackle this on three main fronts, at a

Government level, a research and intervention level and at a societal level.
The World Health Organization (WHO) declared severe acute respiratory syndrome coronavirus 2 (SARS-CoV-2), otherwise known as COVID-19, as a pandemic on the 11th of March 2020 (Huang et al., 2020; Pappa et al., 2020). For those healthcare professionals (HCPs) working on the frontline (both COVID specific and non-COVID specific work), recent pandemic research has highlighted that COVID-19 is likely to have a profound impact, both mentally and physically. Previous literature (specifically referencing severe acute respiratory syndrome known as SARS and Middle East respiratory syndrome-related coronavirus), known as MERS-coV), has demonstrated that the circumstances surrounding epidemic and pandemic outbreaks for HCPs such as exposure and infection risk to self or colleagues, stigma, witnessing of death and exposure to other traumas, occupational stress (e.g. redeployment, lack of resources, poor organizational support), isolation from loved ones due to concerns about passing the disease to family, and loneliness are major risk factors that can profoundly impact mental health and wellbeing (Cai et al., 2020; Greenberg, Docherty, Gnanapragasam, \& Wessely, 2020; Kim, 2018; Maunder et al., 2008; Santarone, McKenney, \& Elkbuli, 2020; Spoorthy, 2020). It is important to acknowledge the inherent resilience and dedication of HCPs during the COVID-19 outbreak, despite the great personal risk (Liu et al., 2020). However, it must also be acknowledged that HCPs are not invulnerable to the psycho-social impact of this virus (Spoorthy, 2020). HCPs have been found to be at an increased risk of developing PTSD (Carmassi et al., 2020) and other forms of psychopathology such as chronic stress, anxiety or depression (McAlonan et al., 2007) during pandemic situations. Moreover, the complex interplay between the situational and dispositional factors that increase the risk of psychopathology to HCPs, and their resilience to buffer this impact, becomes increasingly more challenging to understand in the unprecedented context of COVID-19. It is also difficult to ascertain or anticipate the needs of HCPs, as this situation continues to evolve and change (Carmassi et al., 2020).

Early research from both China and Italy investigating the psychological impact of the COVID-19 outbreak on HCPs has, unsurprisingly, yielded similar results to previous pandemic literature. Specifically, several demographic (such as female gender, available levels of social support) and occupational (infection exposure and concern when caring for COVID-19 patients) factors were significantly associated with negative mental health outcomes, such as clinically relevant levels of anxiety and depression, together with increased 
levels of stress across both medical and non-medical HCPs (Lai et al., 2020; Rossi et al., 2020; Spoorthy, 2020; Xing, Sun, Xu, Geng, \& Li, 2020; Zhang et al., 2020). Pappa et al. (2020) examined 13 studies $(\mathrm{N}=33,062)$ relating to the mental health outcomes of HCPs during COVID-19; Pappa and colleagues collectively found that $23.2 \%$ reported probable anxiety, $22.8 \%$ reported probable depression, and $38.9 \%$ reported insomnia. A recent qualitative study examining HCPs' (specifically nurses and doctors) experiences of caring for COVID-19 patients in China indicated that HCPs felt a sense of duty and care towards their patients, whilst also facing a range of both physical and mental challenges associated with working within a completely new context amid a pandemic (Liu et al., 2020). Liu and colleagues' study uncovered several key insights from the perspective of HCPs, leading to specific recommendations that could improve wellbeing, reduce stress within the workplace and improve the working environment.

Notwithstanding important key COVID-19 commentary pieces (Greenberg, Brooks, Wessely, \& Tracy, 2020; Willan, King, Jeffery, \& Bienz, 2020), little research has directly examined mental health and wellbeing of frontline HCPs specifically within the UK. This is despite the high prevalence of COVID-19 related cases and deaths within the UK. Moreover, it does not appear that any research to date has employed qualitative methodologies to examine the lived experiences of working HCPs, that were based in any of the four UK nations, during the COVID-19 outbreak. Detailed insights from qualitative studies on HCPs' mental health and wellbeing can inform larger scale quantitative studies. Furthermore, qualitative findings can inform potential interventions to improve HCPs' wellbeing, ensuring they have adequate resources to navigate this stressful working environment and maintain both their physical and psychological health.

At present, the limited extant literature has a focus on nurses and doctors despite a broader range of HCPs having close contact with patients. Therefore, the current study aimed to build upon the findings of Liu et al. (2020) by broadening the scope of study to explore the experiences of a wider range of HCPs (e.g. paramedics and mental health workers). Specifically, the aim of this study is to examine the lived experiences of a range of UK based HCPs, with a particular emphasis on how personal experiences and contextual factor influence psychological wellbeing among frontline HCPs. Moreover, to the authors' knowledge, this is the first study to qualitatively examine the lived experiences of a range of UK based HCPs; specifically those in Northern Ireland (NI) (one of the $4 \mathrm{UK}$ nations), that were actively working in a frontline capacity during the early stages of the UK lockdown period (interviews were conducted between 14.04.20 and 29.04.20).

\section{Method}

\subsection{Study design}

This qualitative study adopted a phenomenological epistemological stance to explore the subjective experiences of individuals and how they made sense of their internal and external world (Smith, Flowers, \& Larkin, 2009). Interpretative Phenomenological Analysis (IPA) (Smith et al., 2009) facilitated an indepth exploration of narratives detailing the lived experience of HCPs working during the COVID-19 outbreak.

\subsection{Setting}

This study involved participants who currently were HCW's based in Northern Ireland (NI). Healthcare within NI, like the other three nations of the UK (England, Scotland and Wales), has its own system of publicly funded healthcare. In NI, what is known as the National Health Service (NHS) elsewhere is referred to as Health and Social Care (HSC). There are five 'Trusts' within the HSC that provide a range of medical, psychological, social and other welfare services across the entirety of NI (Northern Trust, Western Trust, Belfast Trust, Southern Trust and South Eastern Trust). The participants within the current study worked within the context of the HSC, primarily in nursing roles, social work roles or mental health practitioner roles.

\subsection{Participants}

Participants were eligible for inclusion if they were (1) over 18 and (2) HCPs that were currently working across NI during the COVID-19 pandemic. This included, but was not limited to, doctors, nurses, midwives, paramedics, social workers, care workers, and other frontline health and social care staff. This afforded the opportunity to explore a range of working environments and personal experiences by including a sample with sufficient variation of experiences within the healthcare sector during the COVID-19 pandemic (Orri et al., 2014; Patton, 2014). Ten HCPs participated in the study. Overall, the majority were female $(n=7 ; 70 \%)$, with an age range from 25 to 56 years $(M=41 ; S D=11.43)$. The majority were married $(n=8 ; 80 \%)$ and had at least one child $(n=6 ; 60 \%)$. Participants worked across sectors including, nursing, ambulance service, mental health, midwifery and social care. Most of the participants $(n=9 ; 90 \%)$ worked directly with patients in a hospital or GP context, with one participant working in a care home setting. All HCPs were in direct contact with patients. In the context of the mental health and social care professionals, they had a period of working directly with patients prior to and during the lockdown, before moving to telephone work at the time of interview. 


\subsection{Recruitment}

Participants were recruited via social media (Twitter, Facebook and the University website), and also through snowball sampling. Recruitment ceased when sufficient data were collected which provided a rich insight into the experiences of frontline HCPs, denoting data saturation (Smith et al., 2009).

\subsection{Data collection \& procedure}

Participants who expressed an interest in taking part were provided with a participant information sheet and consent form. Once consent was provided an interview was arranged and conducted at the participant's convenience. All interviews were conducted by two members of the research team, both interviewers are BPS accredited Low-Intensity CBT practitioners and each have several years' experience in the area of conducting patient-centred interviews and research in the area of applied mental health and wellbeing.

A semi-structured interview approach was used in the current study. This was deemed appropriate for several reasons. Firstly, semi-structured interviews are among the most commonly utilized approaches within the area of qualitative research (DeJonckheere \& Vaughn, 2019). Secondly, semi-structured interviews have been commonly employed across a range of applied mental healthrelated qualitative studies (Brooks, Gerada, \& Chalder, 2017; Reid, Escott, \& Isobel, 2018). Finally, this approach enabled the research team to ask open-ended questions in order to allow participants to convey their thoughts, feelings and experiences without being lead or biased by the interviewer (DeJonckheere \& Vaughn, 2019). This approach, therefore, is optimal for allowing participants space to expand upon personal or sensitive issues, and/or, provide important new information about the research topic that the interviewer was previously unaware of, while also keeping the interview focused (Jamshed, 2014). The interview schedule was developed based on the findings of the available COVID-19 related empirical literature, as well as the extant literature of previous pandemics (e.g. SARS and MERS-coV) which examined the circumstances surrounding epidemic and pandemic outbreaks for HCPs. This was not piloted.

All interviews (semi-structured) were conducted over the telephone, with the duration ranging from 40 to 98 minutes ( $M D=1$ hour 11 minutes). Interviews took place during the lockdown period issued by the UK Government (14.04.20-29.04.20). During this time period, the first official UK lockdown was extended for a further three weeks, subject to review after this period. However by early May, the number of reported deaths in the UK was the highest in Europe and the second highest worldwide (Please see, Armour, McGlinchey, Butter, McAloneyKocaman, \& McPherson, 2020 for a detailed breakdown for both the COVID-19 disease course and lockdown restrictions in the UK during the time of the study).

Demographic information was collected before each interview. Open-ended interview questions included topics such as differences between their working environment prior to the outbreak and during COVID-19, challenges to working across new contexts, patient care, mental health and coping. A stress management protocol was formulated to be followed if any participant became distressed, however, there were no incidents requiring the implementation of the protocol.

All interviews were audio-recorded and then transcribed verbatim. To protect participants' identities, each participant's name was replaced with a pseudonym. Additionally, the participants characteristics (in relation to their demographic information) are presented as a group to further preserve anonymity. Ethical approval was granted by the faculty of Engineering and Physical Sciences at Queen's University Belfast (EPS 20_102).

\subsection{Sample size}

A sample size of 10 was considered adequate for the current study for three reasons. Firstly, the extant literature suggests that smaller sample sizes are more appropriate in the context of IPA analysis given the nature of the approach (Smith et al., 2009). Typically, a sample ranging from 4 to 10 participants is recommended (Clark, 2010). Secondly, several qualitative studies in the area of applied mental health have sample sizes of approx. 6 - 11 participants (Beattie, Murphy, Burke, O'Connor, \& Jamieson, 2019; Eriksen, Sundfør, Karlsson, Råholm, \& Arman, 2012; Knight, Wykes, \& Hayward, 2003). Finally, recruitment ceased when the point of data saturation was reached. Saturation in this context means at a certain point no new 'data' or 'themes'/'codes' are emerging from within the data (Vasileiou, Barnett, Thorpe, \& Young, 2018). This is a commonly employed tool to determine adequate sample size within qualitative research and is considered the gold standard (Fusch \& Ness, 2015; Vasileiou et al., 2018).

\subsection{Analysis}

To ensure a detailed examination of individuals interpretations of their lived experiences, IPA was used to analyse the transcripts (Smith et al., 2009). IPA is an approach which centres on examining the lived experience of the individual by drawing from the concepts of phenomenology, hermeneutics and idiography (Noon, 2018). The goal of IPA is to explore how individuals perceive themselves and the world around them (Noon, 2018; Smith \& Osborn, 2003). Given the unprecedented nature of the COVID-19 pandemic, IPA was deemed appropriate for two key reasons; (1) the study's focus (the lived experiences of HCPs working during the COVID-19 pandemic and the impact 
that working as an HCP had on their psychological wellbeing); and (2) IPA has been utilized in similar studies involving HCPs and is deemed a useful technique to explore experiences in health contexts (Pringle, Drummond, McLafferty, \& Hendry, 2011; Volpato, Banfi, Valota, \& Pagnini, 2018).

As stated above, IPA is a multistage process which centres on phenomenology and hermeneutics; it is an inductive approach which ensures that themes derived are closely bound to the data (Smith et al., 2009). Themes were developed during the analysis process, not prior. In order to do this firstly, all transcripts were read several times to gain a thorough understanding of what the participants were conveying. During this stage, key quotations were highlighted, general thoughts/impressions were noted, and initial codes regarding potential themes were made for each transcript. Next, a preliminary list of themes that emerged from the range of transcripts was generated and connections between themes (or clusters of themes) were identified. The research team then met to discuss the preliminary list of themes (superordinate and subordinate) and to develop a detailed description of their meaning. Themes were agreed upon and finalized by the research team. Finally, an ordered table of superordinate and subordinate themes was produced.

\subsection{Credibility and trustworthiness}

Several steps were taken to ensure the trustworthiness and credibility of all analysis detailed in the current study. Firstly, it is important to recognize that experiences of participants are understood through the subjective interpretation of the researcher (O'Mullan, Doherty, Coates, \& Tilley, 2019). Therefore, it is important to note that those conducting interviews (two researchers) are mental health practitioners who practice continued self-reflection regarding their clinical work. This experience allowed the interviewers to be aware of, and attempt to, set aside their preconceptions immediately before each interview. Additionally, peer debriefing was carried out following every interview. This afforded the interviewers the opportunity for continued self-reflection throughout the entire process, where preconceptions and assumptions could be acknowledged and carefully considered as an ongoing process (Elo et al., 2014). The wider research team met to discuss and compare the initial findings, and to agree on super/subordinate themes. Any variation between participants' accounts were considered and attempts were made to select and report appropriate quotes to fully reflect participants' authentic lived experiences (Elo et al., 2014; Liu et al., 2020)

\section{Results}

IPA was used to examine the lived experiences of 10 HCPs operational as frontline workers during the
COVID-19 pandemic. Three superordinate themes, with subordinate themes, were elicited through the analysis (see Table 1). The first theme broadly highlighted present and future challenges of HCPs working during the pandemic. The second theme captured the mental health and wellbeing of HCPs and theme three centred on HCPs' perceptions of the attitudes of the public towards HCPs.

\subsection{Present and future occupational and caregiving challenges working during the COVID-19 pandemic}

Superordinate theme one focuses on key logistical and work-related challenges that the participants experienced during the early stages of the pandemic. Specifically many participants experienced notable changes to their working roles. Additionally, many faced key logistical challenges such as lack of resources and equipment, and reflected on the impact these occupational challenges has had on patient care and on their personal lives.

\subsubsection{Infection concern}

Given COVID-19 is highly contagious, there is a lack of understanding of how the disease spreads and there is no effective treatment, all participants were fearful of contracting the disease. For many, this fear stemmed not from contracting COVID-19 themselves but from concern for 'passing it onto our patients who are very vulnerable.' (Mark) and loved ones at home. Many expressed that they now often lived with a high degree of hypervigilance. Participants were frequently exhausted by the intensive cleaning processes involved in efforts to try to prevent the spread of infection.

It's exhausting trying to not pass it on to your own family. It is constantly on your mind. - Hannah

Moreover, many participants expressed that they had to put their faith in the PPE that is fitted properly and trust that the equipment would keep them safe. However, this was challenging for participants in cases where different types of PPE were administered at different time points. Some participants knew that

Table 1. Summary of superordinate and subordinate themes.

\begin{tabular}{l}
\hline Superordinate Theme 1. Present and Future Occupational and Caregiving \\
Challenges working during the COVID-19 Pandemic \\
\hline (A) Infection Concern \\
(B) Challenges of Working within a New Context \\
(C) Resource Availability and Concerns \\
(D) Future Challenges to Delivering Patient Care \\
Superordinate Theme 2. Mental Health \& Well-being \\
(A) Impact on Mental Health \\
(B) Resilience \& Coping \\
(C) Impact of Patients' Experiences \\
Superordinate Theme 3. Perceptions of Public Attitudes towards HCPs \\
(A) Perceived Stigma \\
(B) Community Spirit - The Importance of Morale \\
(C) Messages to the Publi
\end{tabular}


'they were short in some areas of them higher grade masks ... whether that has fixed itself I'm not sure; there was a lot of, kinda', going to different areas and different places and moving a lot of stock around.' (Robert). There were concerns over the utility of PPE.

All participants expressed the impact COVID-19 and infection management had had on patient interpersonal care - whether they are COVID-19 positive or not. Many expressed that at the very least patient care would be of an inferior quality, especially when decisions relating to risk were 'against your training ...' (Robert). Kevin affirmed the impact on the quality of care by admitting 'that's not the best standard of care, but that's the best way to keep ourselves safe and everyone around.'

Participants felt that there were now barriers between themselves and their patients which was distressing. All HCPs discussed the importance of 'non-verbal cues' (Ann), physical touch and communication in the context of patient care. However, due to safety restrictions and PPE made this aspect of care extremely difficult, as explained by Kevin '... when interacting with patients would be kind of facial cues and, em, kind of, you know, a comforting hand on the shoulder and things like that ... we can't do that anymore, um, not to mention you know we're going into every patient with a mask and face shield on, and they can't, they can't see us, um, so it's very hard to kind of comfort in a way that you would've before ...'

All HCPs were concerned at their inability to ease patients' fear or discomfort, which was extremely upsetting for both the patients and HCPs. Some participants reflected on the difficult decisions they had to make regarding the risk of infection spread. Kevin explained that he was 'more hesitant' to physically engage with patients due to an infection risk, whereas before he wouldn't have paused. Kevin commented that within his role it was natural, appropriate and sometimes necessary to be tactile, especially 'with elderly patients who can't really hear or see you well'. Furthermore, not being able to relieve patient discomfort caused HCPs to feel frustrated and helplessness as expressed by Ann 'you just feel so helpless in that there is nothing we can tangibly do to make these people feel better and feel better quickly.'

\subsubsection{Challenges working within a new context}

All participants experienced a multitude of changes regarding their working environment, bringing logistical and personal challenges to their 'new role'. These changes to their role and working location were often sudden, as described by Hannah ' ... changes are not even on a daily basis. It changes on an hourly basis.' While many participants acknowledged that the change was both necessary and unavoidable, changes still created a high degree of anxiety and unease, which had an emotional impact. One participant (Sam) epitomized the impact by expressing 'we are devastated' with no resolution. Participants expressed feelings of uncertainty and fear over next steps, which affected themselves and their loved ones.

Concerns over the impact of working during the pandemic on family life was noted by all participants. Concerns included ' ... how am I to manage single parenting' (Ann) and ' ... it's more the worry of knowing how long I might have to do it for as well ...' (Robert).

Furthermore, those participants that underwent redeployment faced challenges including longer commutes, separation from a familiar location and a split from a strong support network of trusted colleagues.

That was just dropped on us. There was no negotiations, there was no 'these are your options, you might not have to go there' ... the thought of moving again to a different hospital almost an hour away is too much for me .... - Ann

And again, that removed another support mechanism from you because you know you need your family around you for the support when you do come home. - Hannah

Many HCPs felt ill-equipped or fearful about tackling new roles, particularly those working within a hospital context. Being redeployed to the intensive care unit, which was 'their [patients] last line of defence' required 'a lot of expertise for a specialized unit', therefore brought a great deal of 'anxiety and worry' (Ann). Redeployment came with a sense of great responsibility for patients and which some participants described with as a sense of being overwhelmed.

Participants expressed there was a high degree of confusion due to receiving 'mixed messages' (Sarah), particularly in the early stages, from both the wider UK government and the upper management regarding personal protective equipment (PPE) availability and usage, social distancing practices and the impact of COVID-19 on the daily logistics of their jobs. Such confusion created feelings of uncertainty and anxiety, as well as frustration as 'everybody needs to be taking a similar approach.' (Sarah). The rapid change in messages is conveyed by Zoe who commented that 'one week we're being told "oh you should be wearing masks" and the next day they are like 'no, actually [message change] ...' A lack of clear information, coupled with stark changes to roles and working conditions, led many to feel unvalued and disposable; this thought weighed heavily for many participants.

We work in a caring profession but you don't feel cared for. - Ann

\subsubsection{Resource availability and concerns}

Availability of PPE and other essential resources was a source of constant worry for majority of participants as they were 'very aware that there is limited amounts of PPE' (Hannah). Participants expressed that they often had to take each week as it came, with some not knowing whether they would have enough 
resources for the week ahead. Unavailability of PPE, and fear of not having enough going forward, led many participants to struggle with feelings of guilt for using PPE. Many therefore tried to take conscious steps in order to not 'waste' PPE, as described by Hannah 'The equipment is disposable, so everything you wear, each time you put it on, that's why it's trying to balance between not wasting PPE by going in and out and actually keeping yourself safe and having the right equipment ...'

Action to avoid PPE wastage subsequently had an effect on the physical wellbeing of the staff.

... during our 12 hour shift you are entitled to an hour's break, but the best way to do it is to have two half hour breaks. It's not really a half hour break though because when you come out, by the time you have logged off and on that takes maybe 5-10 mins either side to do it properly. You get a drink of water. You could eat but there is very little time to do that. I basically have a drink of water and then put on the equipment again because other people are waiting for their breaks and go back in ... Once you are in you can't really come out just to go to the toilet because it wastes PPE ... you are starting to get dehydrated because you can't drink or anything. If you do drink you feel like you need to go to the toilet so you are just basically there with a headache and pain in your face, pain in your sinuses, and just an absolute thumping headache whilst you are working, so it's very hard to tolerate it is. - Hannah

For those working in the GP surgeries as mental health or social workers, there was an expressed concern about different types of staff wearing different levels of PPE. Sarah commented that 'the GPs have moved to wearing scrubs' whereas 'we've [non-GPs] been going to work in our ordinary clothes ...' despite both types of HCPs facing the same COVID-19 contagion risks associated with face-toface patient contact. The experience of inconsistent working practices undoubtedly stemmed from a lack of thorough consideration of all HCPs' working environments and contributed to the anxiety experienced of working on during the pandemic outbreak.

\subsection{Future challenges to delivering patient care}

HCPs conveyed concern about the future of both physical and mental health. Specific worries related to growing waiting period for those with health conditions that were down-prioritized, those with mental health disorders who had already been placed on a long waiting list and those experiencing mental ill health in relation to COVID-19 experiences. Many services and patients were effectively 'put on hold for this [COVID-19]' (Hannah). There was great anxiety over what the longer-term impact would be and whether services were equipped to handle this. As
Sarah pointed out, going forward 'there's only so many appointments available in a week.'

Additionally, for those HCPs who have provided support via telephone/online methods, a number of concerns were expressed relating to interpersonal care. Mark commented that there 'are the people there that, you know, are going to suffer because nobody can get out to them ...', referring to patients that did not have adequate access to technology or that had no experience using it. There were concerns over an inability to sufficiently gauge patient safety in relation to safeguarding (e.g. domestic violence) and a sense of worry that those with 'hidden' needs would be missed. Switching to virtual care as opposed to face-to-face care had the potential to let some members of the community 'fall through the cracks'.

The majority of participants expressed deep concerns over the impact of grief and bereavement on those who have lost loved ones during this time. Specifically, this related to those who felt they had not been allowed to say goodbye to their loved ones and they had not grieved.

They don't have the opportunity to be dealing with their grief the way that we in Northern Ireland usually deal with our grief, which is, your family and your friends are at the house all the time, and, you're, you know, you're able to go and visit the grave, and, you know, the wake almost goes on for three-four weeks after the person has passed away. Sarah

In sum, within the context of superordinate theme one; participants discussed the impact that a multitude of changes regarding their working environment had, both logistically (resource availability and management, redeployment, patient care) and personally (impact on family life, fears of passing the infection on to colleagues, patients or loved ones), leaving many feeling overwhelmed, confused and undervalued.

\subsection{Mental health \& well-being}

Superordinate theme two centres specifically on the mental health and wellbeing of the HCWs themselves. Participants specifically reflect on how their work-related experiences have impacted their mental health, however, this was also accompanied with discussion relating to how HCWs use different coping strategies to manage the stresses of their work life.

\subsubsection{Impact on mental health}

The majority of participants explained that their experiences impacted their mental health in a variety of ways. Sarah considered that 'they are sending me to my death'. The gravity of the situation brought anxiety and fear for most. Many expressed experiencing a range of emotions while trying to work within the pandemic, as demonstrated by Hannah, 
I suppose just the range of emotions that you feel. Just you know from feeling positive to just feeling scared and terrified and coping with the physical side as well, the PPE is just hard.

The physical exhaustion associated with PPE and intense cleaning procedures left many HCPs feeling exhausted, especially after ' ... a 13-hour day' (Ann). Many explained they had little time to relax as they had to ' ... do this [contagion minimizing behaviour] and do that $\ldots$.. and it's another hour' (Ann), which impacted mental health.

Redeployment also brought a sense of reduced well-being. Social support received through wellformed working relationships was now missing. Sam commented that 'whilst the ladies are lovely, lovely where I've just gone, you know, my work colleagues now, I don't know them. I don't know them', so working in an unfamiliar setting with unfamiliar people potentially impacted mental health further.

\subsubsection{Resilience \& coping}

All participants demonstrated resilience and adaptability within this crisis, which may seem somewhat contradictory to previous comments expressed by the participants. The majority of participants expressed what could be defined as a 'call to duty' or an acceptance that this is their job. Hannah confirmed ' ... this is what I trained to do, you know, I never really thought there would be a pandemic but at end of the day this is why I trained'. There was a strong sense of 'people need us and that's just it' (Alice). All participants endeavoured to move forward and 'do their job'. As 'the thing that always keeps us going ... it's the patients' (Hannah). HCPs continued to show resilience, and work despite great personal risk.

Many participants tried to build resilience through a positive mindset by embracing the opportunity to learn new things this new working context has brought them. Hannah reflected that 'we will all come out of this stronger people plus we will also learn skills that we never had ... . it is something positive to come out of it. I am learning new skills.' Nevertheless, resilience of the HCPs was accompanied with concern over the longer-term impact and whether this degree of resilience can be maintained. Many felt their 'resilience waning a bit' (Patricia).

Many HCPs expressed they sought to have a positive outlook and adopt a range of positive coping strategies to help manage difficult emotions. Additionally, many acknowledged they had access to therapeutic support within their respective employment. Patricia commented ' ... it's been a really, really, positive experience for me to see that the support is there.'

All participants unanimously expressed that they sought comfort in the 'little things' to cope with stress such as 'being with family ... talking about it ... . having a faith and praying ... watching TV ... the walks are great' (Ann). Participant generally reported engaging in similar activities to help them cope and explained how particular activities acting as a coping tool. For example, Ann explained that walking helped to switch off and reading books helped with sleep, therefore, each activity had a purpose.

Some did reflect that certain coping strategies may be unhealthy or maladaptive, however, a particular method of coping had become a default stress management strategy. Hannah demonstrated this by commenting 'I probably block a lot of it out to be honest ... I have kind of just learned to put a difficult day to the back of my mind ... I suppose that is something I have done for a long time, which is probably not the right thing to do but that is the way I have kind of got through difficult periods.'

Social support emerged as a crucial healthy source of support for mental health, particularly from colleagues. HCPs expressed that having a sense of togetherness among their colleagues and being able to discuss problems with trusted people who have shared experiences and an understanding of their unique situation made coping easier.

We're all in the same boat, and we're all coming to
the same workplace, and we all work in the same
way, em, I would say they probably are in similar
mindsets. Like, based on conversations and stuff
we've had, everyone's kind of the same, obviously
people's rollercoaster of emotions are at different
times, em, but we work with it, you know, and we
all just chat about it ... I would say everyone
probably is in the same kind of mindset, which is
good, cos then we're all able to kind of help each
other. You know, we're still all being supportive of
each other which is good. - Zoe

\subsubsection{Impact of patients' experiences}

HCPs were impacted by the experiences of the patients themselves, with many recalling distressing situations which have stayed with them. For those delivering medical care the indirect effects the disease was found to be distressing. COVID-19 brought isolation restrictions which meant some struggled with self-care. Family members with specific needs were not cared for due to safeguarding, which put patient health at further risk. There were 'people that were going into hospices ... but there isn't any visiting. The family are saying goodbye so that person in your ambulance [before they die] ...' (Kevin). It was upsetting for HCPs to watch families' 'say goodbye' while the person was still alive as the reality was the family could not be there at the point of death.

In sum, superordinate theme two focused specifically on the mental health and wellbeing of the participants. All participants conveyed their ability to adapt and demonstrate resilience during this difficult time; however, this was accompanied with real concerns over their ability to maintain this overtime. 
Additionally, social isolation from loved ones, separation from important work place social networks due to redeployment, as well as physical exhaustion due to the demands of the job, impacted participants mental wellbeing.

\subsection{Perceptions of public attitudes towards HCPs}

The final superordinate them focused on how HCWs felt they were perceived by the public. This encompassed both feelings of perceived stigma, as well as a sense of community support in some cases. Most importantly this superordinate theme outlines a collection of key messages which each HCW involved in the current study wished to convey to the public to help them understand what they are experiencing during this unprecedented time.

\subsubsection{Perceived stigma}

Participants commented that they felt stigmatized by members of the general public. HCPs expressed upset at experiences where they noticed the public were 'afraid of us as well' (Kevin) while they were in uniform outside work because 'I could have something and spread it to them' (Zoe). Some experienced verbal abuse in shopping environments, for example Zoe explained they were actually badmouthing me for not waiting to cue'. This sense that the public were afraid and even abusive caused the HCPs to feel undervalued. The seeming misunderstanding of what certain keyworkers did, and why HCPs were given priority in places such as shops, caused some to feel very annoyed and disheartened.

... it really annoyed me cos I was like you are the people who go out and clap at 8 o'clock every Thursday, and you're all like "oh this is brilliant, people are out on the front line being key workers, woo", and then until it like directly impacts on their life, they're like "aw it's great" and then you bumped in front of them in a queue and they're like "ugh, I can't believe she just did that ..." , and it's really annoying. - Zoe

\subsubsection{Community spirit}

Despite stigma directed at HCPs, all participants expressed feelings of gratitude for acts of kindness and support received from members of the public. Some participants recounting instances where communities had made face masks and eye shields for HCPs, had offered kind words, had performed thoughtful deeds and 'had kept morale up' (Kevin).

Many HCPs expressed that the community spirt and morale boost from the public allowed them to feel seen and their work was appreciated for the first time. Zoe epitomized this by saying 'think a lot people yanno' seen us and didn't really understand what we did before ... the whole health and social care sector it's needed.'

\subsubsection{Messages to the public}

Many expressed mixed feelings regarding the public; there were those who were kind but also those who were not adhering the lockdown restriction regulations (at the time of interview which took place between 14.04 .20 and 29.04.20).

I think at the start, I think, think there was, there was an awareness at the start and people were taking it seriously, but I think in the last, in the last few days to weeks, that's changed. - Kevin

Each of the ten HCPs expressed messages that they wished to convey to the public, to help the public understand the HCPs' experiences and appreciate the reality of this pandemic more clearly. The clear message was that 'everyone has an individual responsibility during this ...' (Hannah). Ann became quite emotional when she pleaded with the public that 'if they could see what it is like to be so short of breath that you can't speak or hold your head up or ... totally exhausted and incapacitated. If they could see what this disease does to people they would stay in their houses'.

HCP's also made requests of the governing bodies for adequate resources such as PPE and clearer public health information. It was reasoned that 'it's probably why a lot of people aren't following the guidelines, because they are very confusing' (Zoe).

In sum, superordinate theme three summarized participants concerns over how HCWs were/are perceived by the public and governing bodies. Many felt stigmatized, undervalued and misunderstood. However, this was also accompanied by an appreciation for the sense of community spirit convey by the general public in order to support their essential work during this pandemic. Most importantly all HCWs wished to press upon the general public the seriousness of the disease.

\section{Discussion}

Preliminary quantitative research has examined the prevalence of mental ill health and the factors associated with mental ill health among HCPs during the COVID-19 pandemic, but to date little is known about the lived experiences of HCPs working during this time (Lui et al., 2020). The current study examined the lived experiences of 10 HCPs based in NI using IPA. Overall it is clear while all HCWs involved within the current study demonstrated a marked resilience and ability to cope effectivity with the stresses they are experiencing as part of their job role, there are some key areas of concern. Specifically, in relation to work-related challenges (e.g. infection concern, resource availability, redeployment, change of duties, impact of patient experiences) as well challenges to future patient care in light of these challenges. Additionally, despite the resilience of the sample, concern was also raised about how well-being among HCWs can be maintained and how HCWs can be supported as the situation continues to unfold. 
Most participants demonstrated a marked resilience and dedication to their work and the patients/service users in their care, despite the increased risk of infection to themselves and their loved ones. Additionally, all participants employed a range of coping strategies to mitigate the physical and emotional toil that working during a pandemic has taken, such as seeking social support from loved ones, enjoyable and/or relaxing activities or new hobbies. This is in line with previous literature (Lui et al., 2020). Moreover, specifically, the role colleagues played with regards to social support was an integral part of maintaining wellbeing for many HCPs. Despite this, however, the impact on HCPs mental health was apparent, demonstrating increased levels of anxiety, hypervigilance, fear, physical exhaustion and sadness. Some expressed that whilst they are resilient, they are unsure how long the resilience will last in uncertain times, previous COVID-19 specific and previous pandemic research has demonstrated that for HCPs unforeseen and rapid changes to the working environment can negatively affect those that were previously psychologically resilient (Huang et al., 2020). These changes, in turn, increase vulnerability to a variety of poor psychological outcomes such as anxiety disorders, depression, sleep problems and PTSD among HCPs (Lu, Wang, Lin, \& Li, 2020; Pappa et al., 2020). Further, the findings of this study echo a recent UK COVID-19 survey based study, which demonstrated that, in comparison to the general public, HCPs during the UK lockdown period were significantly more likely to experience higher levels of anxiety, depression and PTSD (Murphy et al., 2020; preprint).

Unsurprisingly, occupational and caregiving challenges experienced by HCPs emerged as a superordinate theme, including issues such as infection concern, redeployment, isolation from family, resource availability, PPE safety and barriers to patient care were additional stressors to combating the disease itself. These challenges are arguably intertwined with the theme of 'Mental Health \& Wellbeing'. Previous empirical literature examining the impact of pandemics on HCPs, as well as preliminary research from China and Italy, suggests there are several factors (e.g. increased workload, exposure to death, difficult medical choices and barriers to patient care, resource availability, the impact of patient experiences, infection/exposure concern, exhaustion, isolation from loved ones and lack of social support) linked to mental ill health among HCPs specifically (Khalid, Khalid, Qabajah, Barnard, \& Qushmaq, 2016; Lai et al., 2020; Lui et al., 2020; Rossi et al., 2020; Spoorthy, 2020; Pappa et al., 2020; Xing et al., 2020; Zhang et al., 2020). The emerging themes in the current study support this empirical evidence base.

Additionally, regardless of their respective heath care roles, all participants expressed that there was a high degree of confusion due to a lack of clear and consistent communication particularly in the early stages of the outbreak and period of lockdown in the UK, from both the wider UK government and the upper management within their occupation. Specifically, this was regarding PPE availability and usage, social distancing practices and the impact of COVID-19 on the daily logistics of their jobs which created feelings of uncertainty, anxiety and frustration. This is supported by previous pandemic research, finding that a lack of clear guidance and support, sufficient communication and enough resources/ equipment to continue to do their work properly is associated with higher degrees of distress among HCPs (Lancet, 2020; Shanafelt, Ripp, \& Trockel, 2020). Specifically, in the context of this study, sudden and drastic changes to the working environment, uncertainty about the availability and safety of PPE and lack of clear communication and information, led some HCPs to feel unvalued and disposable, which has been echoed in previous research (Shanafelt et al., 2020).

HCPs (both medical and non-medical) are an essential workforce required to combat and treat the devastating impact this disease has had (and continues to have) on the population, as well as combat the wider complications and long-term effects (medical, psychological and societal) a pandemic creates. It is clear from the findings of the current study, coupled with those from preliminary studies investigating the mental health of HCPs during COVID19 , that being a HCP during this time is accompanied by personal cost and has the potential to put pressure on one's psychological state (Greenberg et al., 2020). Therefore, supporting HCPs physical and mental health should be tackled at three levels: (1) Government level, (2) research and intervention level and (3) societal level. At government level the aim should be to produce clear and consistent guidance to mitigate the risk of both uncertainty and fear and, moreover, to maintain consistency of working environment among multidisciplinary HCP teams. Open communication is also needed regarding the availability of all required resources, including PPE (Cai et al., 2020; Lancet, 2020; Santarone et al., 2020). Furthermore, it is essential that governing bodies, as well as those in management positions within the healthcare sectors, create opportunities to engage with HCPs with a view to alleviate any fears or concerns where possible. It would also be useful if policy could be implemented that granted HCPs access to adequate support resources that may address the mental health needs of those frontline workers that have been psychologically impacted by working during the pandemic. At a research and intervention level, given what is understood remains in its infancy, it is imperative that future research examines not only the prevalence of mental ill health but also the risk and protective factors of mental health outcomes in HCPs. COVID-19 studies using prospective data may identify risk factors for psychopathology development during this time. These new studies could also identify protective factors which may mitigate the risks of working during a pandemic, which in turn will guide intervention efforts (Rossi et al., 2020). Such early 
interventions could consider harnessing adaptive coping strategies such as social support or utilize approaches such as trauma-focused CBT, which could be feasibility delivered in a range of flexible formats (Murphy et al., 2020; Pappa et al., 2020). However, interventions must be guided by empirical evidence in the context of COVID19. Also, intervention feasibility amidst the constraints of COVID-19 needs to be factored. Further consideration should be given to how the psychological well-being of HCPs will be monitored and supported as the COVID-19 pandemic unfolds. Monitoring well-being is pertinent as previous pandemic literature has highlighted symptoms of PTSD or other mental health problems may persist way beyond the pandemic (Lee et al., 2007). Finally, considering COVID-19 at the social level, individuals have a social responsibility to demonstrate compassion towards others during these unprecedented times and to follow the COVID-19 guidelines to support the safety of themselves, loved ones, and those working on the front line.

Several limitations are to be noted, some of which are like that of Lui et al. (2020). Firstly, given the restrictions surrounding a study of this nature during a pandemic, all interviews took place via telephone. Collecting data this way may have influenced the interviewers' abilities to establish an interpersonal connection with the participants and to pick up important non-verbal behaviour. However, both interviewers are low-intensity CBT therapists who have extensive experience conducting therapeutic interventions via telephone work. Secondly, the study could be criticized regarding sample composition. The current study was not limited to a specific group of HCPs (e.g. solely nurses or doctors) nor was it a requirement for the participants to have worked directly with COVID-19 positive patients to be eligible for inclusion in the study. However, this was not the authors' intention. The aim of the study was to not only explore the lived experiences of medical HCPs but also to mental health and social workers, given the limited available evidence examining the impact of the pandemic on other types of HCPs who also work directly with patients/service users. Further, the study contained a 50/50 spilt between medical HCPs and mental health/social care HCPs, which therefore afforded the opportunity to explore any potential variation, whilst exploring common themes across all HCPs' experiences. Therefore, this should also be considered as a strength. Additionally, it is important to acknowledge the participants were HCPs working in NI only and therefore the experiences of the HCPs in this study may not reflect the experiences of others elsewhere in the UK. This is important to consider as infection and death rates vary across the four nations. ${ }^{1}$ Further, the experiences of participants in this study may not reflect those of other HCPs based in NI. It is therefore essential to further qualitative research is conducted which examines the experiences of HCPs within different nations in the UK. Finally, it is important to note that while the interviewers possessed the appropriate training and skills to guide the IPA interview and interpret the data, as mental health practitioners by profession, the nature of the study increases the potential for unconscious biases or pre-conceived assumptions to influence the data collection and analysis. To address this, the team harnessed the diversity of team members who are from different professional backgrounds and disciplines, thus introducing different perspectives for balance. To minimize the potential for verbal or non-verbal cues to bias interviewee responses, team discussions were held prior to the beginning of the interviews, where assumptions about the topic were acknowledged and the role of the interviewer was reflected on. Additionally, peer debriefing was undertaken following every interview, where continued reflection and feedback on the process was discussed within the team. This afforded the interviewers the opportunity for continued self-reflection throughout the entire data collection process, where preconceptions and assumptions could be acknowledged and carefully considered as an ongoing process (Elo et al., 2014). This process of shared reflection continued throughout each phase of data analysis to harness the collective interpretation of the data. To assist this process, the interviewers maintained a separate reflective journal to record the issues about any potential biases or prior assumptions that might influence data analysis for discussion with the wider team. Furthermore, emerging codes and themes were cross-examined throughout the analysis, to ensure that these remained bound to the data. This helped to ensure that interpretation of the data rooted in the stories of participants, and were less influenced by the stories held by the team members analysing the data.

However, despite the established limitations of qualitative research (Patton, 2014), the current study is among the first to examine the lived experiences of HCPs working during the COVID-19 pandemic. To the authors' knowledge, this is the first study to examine this among HCPs in the UK, offering an in-depth detailed examination of their unique experiences as well as the unprecedented circumstances they are currently dealing with.

\section{Note}

1. At present, the total number of lab-confirmed positive cases in the UK is $1,538,794$ and the total number of deaths in the UK (with COVID-19 on the death certificate) is 66,713 (Public Health England, 2020; https:// coronavirus.data.gov.uk/). By nation the total number of deaths in the UK (with COVID-19 on the death certificate) are as follows: Scotland 5,135; England 57,147; Northern Ireland 1,201; and Wales 3,230. Figure is correct as of Tuesday the 24th of November 2020.

\section{Data availability statement}

Participants did not provide consent for their raw data or interview transcripts to be made publicly available to 
researchers beyond those involved in the current study. However, the data corresponding to the paper may be made available upon reasonable request from the first author in conjunction with an appropriate data sharing agreement.

\section{Disclosure statement}

No potential conflict of interest was reported by the author(s).

\section{Funding}

This research received no specific grant from any funding agency in the public, commercial, or not-for-profit sectors.

\section{ORCID}

Emily McGlinchey (D) http://orcid.org/0000-0002-7423-8762 Cherie Armour (1) http://orcid.org/0000-0001-7649-3874

\section{References}

Armour, C., McGlinchey, E., Butter, S., McAloneyKocaman, K., \& McPherson, K. E. (2020). The COVID-19 psychological wellbeing study: Understanding the longitudinal psychosocial impact of the COVID-19 pandemic in the UK; a methodological overview paper. Journal of Psychopathology and Behavioral Assessment, 1-17. doi:10.1007/s10862-020-09841-4

Beattie, D., Murphy, S., Burke, J., O’Connor, H., \& Jamieson, S. (2019). Service user experiences of clinical psychology within an adult mental health service: An IPA study. Mental Health Review Journal, 24(3), 171-182. doi:10.1108/MHRJ-02-2018-0005

Brooks, S. K., Gerada, C., \& Chalder, T. (2017). The specific needs of doctors with mental health problems: Qualitative analysis of doctor-patients' experiences with the Practitioner Health Programme. Journal of Mental Health, 26(2), 161-166. doi:10.1080/09638237.2016.1244712

Cai, H., Tu, B., Ma, J., Chen, L., Fu, L., Jiang, Y., \& Zhuang, Q. (2020). Psychological impact and coping strategies of frontline medical staff in Hunan between January and March 2020 during the outbreak of coronavirus disease 2019 (COVID) in Hubei, China. Medical Science Monitor, 26, 1-16. doi:10.12659/ MSM.924171

Carmassi, C., Foghi, C., Dell'Oste, V., Cordone, A., Bertelloni, C. A., Bui, E., \& Dell'Osso, L. (2020). PTSD symptoms in healthcare workers facing the three coronavirus outbreaks: What can we expect after the COVID-19 pandemic. Psychiatry Research, 292, 113312. doi:10.1016/j.psychres.2020.113312

Clarke, V. (2010). Review of the book "Interpretative Phenomenological Analysis: Theory, Method and Research". Psychology Learning \& Teaching, 9, 57-56.

DeJonckheere, M., \& Vaughn, L. M. (2019). Semistructured interviewing in primary care research: A balance of relationship and rigour. Family Medicine and Community Health, 7(2), e000057. doi:10.1136/fmch2018-000057

Elo, S., Kääriäinen, M., Kanste, O., Pölkki, T., Utriainen, K., \& Kyngäs, H. (2014). Qualitative content analysis. SAGE Open, 4(1), 215824401452263. doi: $10.1177 / 2158244014522633$
Eriksen, K. Å., Sundfør, B., Karlsson, B., Råholm, M. B., \& Arman, M. (2012). Recognition as a valued human being: Perspectives of mental health service users. Nursing Ethics, 19(3), 357-368. doi:10.1177/09697330 11423293

Fusch, P. I., \& Ness, L. R. (2015). Are we there yet? Data saturation in qualitative research. The Qualitative Report, 20(9), 1408.

Greenberg, N., Brooks, S. K., Wessely, S., \& Tracy, D. K. (2020). How might the NHS protect the mental health of health-care workers after the COVID-19 crisis? The Lancet Psychiatry, 19(outbreak1), 30224. doi:10.1016/ S2215-0366(20)30224-8

Greenberg, N., Docherty, M., Gnanapragasam, S., \& Wessely, S. (2020). Managing mental health challenges faced by healthcare professionals during covid-19 pandemic. The BMJ, 368, m1211. BMJ Publishing Group. doi:10.1136/bmj.m1211

Huang, C., Wang, Y., Li, X., Ren, L., Zhao, J., Hu, Y., ... Cao, B. (2020). Clinical features of patients infected with 2019 novel coronavirus in Wuhan, China. The Lancet, 395(10223), 497-506. doi:10.1016/S0140-6736(20)30183-5

Jamshed, S. (2014). Qualitative research method-interviewing and observation. Journal of Basic and Clinical Pharmacy, 5 (4), 87. doi:10.4103/0976-0105.141942

Khalid, I., Khalid, T. J., Qabajah, M. R., Barnard, A. G., \& Qushmaq, I. A. (2016). Healthcare workers emotions, perceived stressors and coping strategies during a MERS-CoV outbreak. Clinical Medicine \& Research, 14 (1), 7-14. doi: $10.3121 / \mathrm{cmr} .2016 .1303$

Kim, Y. (2018). Nurses' experiences of care for patients with Middle East respiratory syndrome-coronavirus in South Korea. American Journal of Infection Control, 46 (7), 781-787. doi:10.1016/j.ajic.2018.01.012

Knight, M. T., Wykes, T., \& Hayward, P. (2003). 'People don't understand': An investigation of stigma in schizophrenia using Interpretative Phenomenological Analysis (IPA). Journal of Mental Health, 12(3), 209-222. doi:10.1080/0963823031000118203

Lai, J., Ma, S., Wang, Y., Cai, Z., Hu, J., Wei, N., ... Hu, S. (2020). Factors associated with mental health outcomes among health care workers exposed to coronavirus disease 2019. JAMA Network Open, 3(3), e203976. doi:10.1001/jamanetworkopen.2020.3976

Lancet, T. (2020). COVID-19: Protecting health-care workers. Lancet (London, England), 395(10228), 922. doi:10.1016/S0140-6736(20)30627-9

Lee, A. M., Wong, J. G., McAlonan, G. M., Cheung, V., Cheung, C., Sham, P. C., ... \& Chua, S. E. (2007). Stress and psychological distress among SARS survivors 1 year after the outbreak. The Canadian Journal of Psychiatry, 52(4), 233-240. doi:10.1177/070674370705200405

Liu, Q., Yang, J., Liu, Q., Luo, D., Wang, X. Q., Phd, Y., ... Liu, Z. (2020). The experiences of health-care providers during the COVID-19 crisis in China: A qualitative study. The Lancet Global Health, 8, e790-e798. doi:10.1016/S2214-109X(20)30204-7

Lu, W., Wang, H., Lin, Y., \& Li, L. (2020). Psychological status of medical workforce during the COVID-19 pandemic: A cross-sectional study. Psychiatry Research, 288 (March), 1-5. doi:10.1016/j.psychres.2020.112936

Maunder, R. G., Leszcz, M., Savage, D., Adam, M. A., Peladeau, N., Romano, D., ... Schulman, R. B. (2008). Applying the lessons of SARS to Pandemic influenza: An evidence-based approach to mitigating the stress experienced by healthcare professionals. Canadian Journal of Public Health, 99(6), 486-488. doi:10.1007/BF03403782 
McAlonan, G. M., Lee, A. M., Cheung, V., Cheung, C., Tsang, K. W., Sham, P. C., ... Wong, J. G. (2007). Immediate and sustained psychological impact of an emerging infectious disease outbreak on health care workers. The Canadian Journal of Psychiatry, 52(4), 241-247. doi:10.1177/070674370705200406

Murphy, J., Spikol, E., McBride, O., Shevlin, M., Bennett, K. M., Hartman, T. K., ... Bentall, R. (2020, June 17). The psychological wellbeing of frontline workers in the UK during the COVID-19 pandemic: First and second wave findings from the COVID-19 Psychological Research Consortium (C19PRC) study. doi:10.31234/osf.io/dcynw

Noon, E. J. (2018). Interpretive phenomenological analysis: An appropriate methodology for educational research. Journal of Perspectives in Applied Academic Practice, 6 (1), 75-83. doi:10.14297/jpaap.v6i1.304

O’Mullan, C., Doherty, M., Coates, R., \& Tilley, P. M. (2019). Using Interpretative Phenomenological Analysis (IPA) to provide insight into female sexual difficulties. Sexual and Relationship Therapy, 34(1), 75-86. doi:10.1080/14681994.2017.1386300

Orri, M., Paduanello, M., Lachal, J., Falissard, B., Sibeoni, J., \& Revah-Levy, A. (2014). Qualitative approach to attempted suicide by adolescents and young adults: The (neglected) role of revenge. PLOS ONE, 9(5), e96716. doi:10.1371/journal.pone.0096716

Pappa, S., Ntella, V., Giannakas, T., Giannakoulis, V. G., Papoutsi, E., \& Katsaounou, P. (2020). Prevalence of depression, anxiety, and insomnia among healthcare professionals during the COVID-19 pandemic: A systematic review and meta-analysis. Brain, Behavior, and Immunity, 88, 901-907. doi:10.1016/j.bbi.2020.05.026

Patton, M. Q. (2014). Qualitative research \& evaluation methods: Integrating theory and practice. Thousand Oaks, CA: Sage publications.

Public Health England. (2020, November). Coronavirus (COVID-19) in the UK. https://coronavirus.data.gov.uk/.

Pringle, J., Drummond, J., McLafferty, E., \& Hendry, C. (2011). Interpretative phenomenological analysis: A discussion and critique. Nurse Researcher, 18(3), 20-24. doi:10.7748/nr2011.04.18.3.20.c8459

Reid, R., Escott, P., \& Isobel, S. (2018). Collaboration as a process and an outcome: Consumer experiences of collaborating with nurses in care planning in an acute inpatient mental health unit. International Journal of Mental Health Nursing, 27(4), 1204-1211. doi:10.1111/inm.12463
Rossi, R., Socci, V., Pacitti, F., Di Lorenzo, G., Di Marco, A., Siracusano, A., \& Rossi, A. (2020). Mental health outcomes among frontline and second-line health care workers during the coronavirus disease 2019 (COVID-19) pandemic in Italy. JAMA Network Open, 3(5), e2010185-e2010185. doi:10.1001/ jamanetworkopen.2020.10185

Santarone, K., McKenney, M., \& Elkbuli, A. (2020). Preserving mental health and resilience in frontline healthcare professionals during COVID-19. The American Journal of Emergency Medicine, 38, 1530-1531. doi:10.1016/j. ajem.2020.04.030

Shanafelt, T., Ripp, J., \& Trockel, M. (2020). Understanding and addressing sources of anxiety among health care professionals during the COVID-19 pandemic. JAMA, 323(21), 2133-2134. doi:10.1001/jama.2020.5893

Smith, J. A., \& Osborn, M. (2003). Interpretive phenomenological analysis. In J. A. Smith (Ed.), Qualitative psychology: A practical guide to research methods (pp. 51-80). London: Sage.

Smith, J. A., Flowers, P., \& Larkin, M. (2009). Interpretative phenomenological analysis: Theory, method and research. London: Sage Publications.

Spoorthy, M. S. (2020). Mental health problems faced by healthcare professionals due to the COVID-19 pandemicA review. Asian Journal of Psychiatry, 51, 102119. Elsevier B. V. doi:10.1016/j.ajp.2020.102119

Vasileiou, K., Barnett, J., Thorpe, S., \& Young, T. (2018). Characterising and justifying sample size sufficiency in interview-based studies: Systematic analysis of qualitative health research over a 15-year period. BMC Medical Research Methodology, 18(1), 1-18. doi:10.1186/s12874-018-0594-7

Volpato, E., Banfi, P. I., Valota, C., \& Pagnini, F. (2018). Psychological support for health professionals: An interpretative phenomenological analysis. Frontiers in Psychology, 9 (SEP), 1816. doi:10.3389/fpsyg.2018.01816

Willan, J., King, A. J., Jeffery, K., \& Bienz, N. (2020). Challenges for NHS hospitals during covid-19 epidemic. The BMJ, 368. BMJ Publishing Group. doi:10.1136/bmj.m1117

Xing, J., Sun, N., Xu, J., Geng, S., \& Li, Y. (2020). Study of the mental health status of medical personnel dealing with new coronavirus pneumonia. Plos One, 15(5), e0233145. doi:10.1371/journal.pone.0233145

Zhang, W. R., Wang, K., Yin, L., Zhao, W. F., Xue, Q., Peng, M., ... Wang, H. X. (2020). Mental health and psychosocial problems of medical health workers during the COVID-19 epidemic in China. Psychotherapy and Psychosomatics, 89, 242-250. doi:10.1159/000507639 